DegruYter DOI 10.2478/v10129-011-0068-0

Kazem Ghassemi-Golezani*, Saeid Ghassemi

Department of Plant Eco-Physiology, Faculty of Agriculture, University of Tabriz, Iran;

Fax:+98411-3345332,*e-mail: golezani@gmail.com

\title{
EFFECTS OF WATER SUPPLY ON SEED DEVELOPMENT AND QUALITY OF CHICKPEA CULTIVARS
}

\begin{abstract}
A split plot experiment (using RCB design) with three replications was conducted in 2012 and seed physiological quality of three chickpea (Cicer arietinum L.) cultivars (Azad, Arman and Jame) was evaluated at seven stages under well and limited irrigation conditions. Maximum seed weight (mass maturity) was achieved at 40-45 days after flowering. However, maximum seed quality was obtained 7 to 10 days after mass maturity, depending on irrigation intervals and cultivars. At earlier harvests, because of immaturity, and at later harvests, due to ageing, seed quality was low. Seed filling rate and maximum seed weight of chickpea decreased with decreasing water supply, but water deficit had no significant effects on seed quality as measured by germination percentage, germination rate and seedling dry weight. Significant differences in seedling dry weight among chickpea cultivars were attributed to significant variation in seed weight affected by genetic constitution.
\end{abstract}

Key words: chickpea; seed filling; seed quality; water supply

\section{INTRODUCTION}

The attainment of high yields depends on many factors including variety, land preparation, weed control, fertilizer, disease and insect control and seed quality. Information about seed quality can benefit farmers in making decisions regarding the cost of seeds, sowing densities and time of sowing. Seed quality, as measured by its vigour and viability, plays a major role in establishment of seedling as well as higher crop yield (Mathews, 1980). High quality seed lots may improve crop yield in two ways: first because

Communicated by Andrzej Aniol 
seedling emergence from the seedbed is rapid and uniform, leading to the production of vigorous plants, and second because percentage seedling emergence is high, so optimum plant population density could be achieved under a wide range of environmental conditions (Ghassemi-Golezani, 1992).

Stage of maturity at harvest is one of the most important factors that can influence the quality of seeds (Demir et al., 2008). Maximum seed quality on the mother plant may be achieved at the end of seed filling phase (mass maturity) which is also described as physiological maturity (Harington, 1972; Tekrony and Egli, 1997; Ghassemi-Golezani et al., 2011a) or after mass maturity (Ellis and Pieta Filho, 1992; Demir and Ellis, 1992, 1993; Sanhewe and Ellis, 1996; Ghassemi-Golezani and Mazloomi-Oskooyi, 2008; Ghassemi-Golezani et al., 2011b) depending on species and type of seed testing (Tekrony and Egli, 1997; Ghassemi-Golezani and HosseinzadehMahootchy, 2009).

Environmental stresses such as water deficit may also influence seed quality development and harvest timing. It was reported that water stress can reduce seed yield, but it has no significant effect on seed quality (Ghassemi-Golezani et al., 1997; Ghassemi-Golezani and HosseinzadehMahootchy, 2009; Ghassemi-Golezani et al., 2010b). In contrast, ZehtabSalmasi et al., (2006) in dill (Anethum graveolens L.) and GhassemiGolezani et al., (2012) in soybean showed that water deficit during grain filling led to significant reduction in seed quality. This research was aimed to evaluate changes in seed physiological quality of chickpea cultivars under well and limited irrigation conditions in order to determine the stage at which maximum seed quality is attained.

\section{MATERIALS AND METHODS}

A split plot experiment (using RCB design) with three replications was conducted in 2012 at the Research Farm of the Faculty of Agriculture, University of Tabriz, Tabriz, Iran (Latitude $38^{\circ} 05^{\prime} \mathrm{N}$, Longitude $46^{\circ} 17^{\prime} \mathrm{E}$, Altitude $1360 \mathrm{~m}$ above sea level) to evaluate changes in seed physiological quality of chickpea cultivars under well and limited irrigation conditions. The climate is characterized by mean annual precipitation of $245.75 \mathrm{~mm}$ per year and mean annual temperature of $10^{\circ} \mathrm{C}$. Irrigation treatments $\left(\mathrm{I}_{1}\right.$, $\mathrm{I}_{2}, \mathrm{I}_{3}$ and $\mathrm{I}_{4}$ : irrigation after $70,100,130$ and $160 \mathrm{~mm}$ evaporation from class A pan, respectively) were located in main plots and cultivars (Azad, Arman and Jam) were allocated to sub plots.

Each plot had 6 rows of $5 \mathrm{~m}$ length, spaced $25 \mathrm{~cm}$ apart. Seeds were treated with Benomyl at a rate of $2 \mathrm{~g}^{\circ} \mathrm{kg}^{-1}$ before sowing. The seeds were then sown by hand on 14 May, 2012, in $4 \mathrm{~cm}$ depth of a sandy loam soil. All plots were irrigated immediately after sowing, but subsequent irrigations 
were carried out according to the treatments. Weeds were controlled by hand during crop growth and development as required.

After seed formation, 5 plants from each plot were harvested in weekly intervals at seven stages. Then seeds were detached from the pods and seed moisture content was determined in accordance with ISTA rules (2010). Subsequently, seeds were dried in an oven at $130 \pm 2{ }^{\circ} \mathrm{C}$ for an hour and seed dry weight of each sample was determined. Seed samples within separate sealed bags were then placed in a refrigerator at $3-5^{\circ} \mathrm{C}$. Seed quality tests were carried out at the Seed Technology Laboratory of the University of Tabriz.

Four replicates of 10 seeds from each sample were tested for germination between double layered rolled filter papers. The rolled papers with seeds were put into the plastic bags to avoid moisture loss. Seeds were allowed to germinate at $20 \pm 1^{\circ} \mathrm{C}$. Germinated seeds were recorded every $24 \mathrm{~h}$ for 8 days. Rate of seed germination $(\bar{R})$ was calculated according to Ellis and Roberts, (1980):

$$
\bar{R}=\frac{n}{D_{n}}
$$

where $\mathrm{n}$ is the number of seeds germinated on day $\mathrm{D}, \mathrm{D}$ is the number of days from the beginning of the test and $\bar{R}$ is the mean germination rate. At the end of each test, numbers of normal and abnormal seedlings were counted (ISTA, 2010) and percentages of germination were calculated. Normal seedlings were then dried in an oven at $75 \pm 2{ }^{\circ} \mathrm{C}$ for 24 hours (Perry, 1977) and mean seedling dry weight for each replicate was determined.

\section{RESULTS}

Analysis of variance of the data showed significant ef-fects of irrigation and cultivar on 100 seed weight. Seedling dry weight was not significantly affected by irri-gation treatments, but it was significantly affected by cultivars. Irrigation treatments and cultivars had no significant effects on germination percentage and germination rate. All parameters of seed quality were significantly influenced by harvest stages. The interaction of irrigations $\times$ harvest stages inter-action was also significant for 100 seed weight, germination percentage, germination rate and seedling dry weight. Interaction of cultivars $\times$ harvest stages was only significant for 100 seed weight and seedling dry weight (Table 1). Thus, regression curves were fitted on mean data of significant interactions in order to show the changes in seed quality parameters at different stages of seed development and maturity. 
Analysis of variance of the effects of different irrigation treatments on seed quality parameters of chickpea cultivars

\begin{tabular}{|c|c|c|c|c|c|}
\hline Source & $\mathrm{DF}$ & 100 seed weight & Germination per- & Germination rate & Seedling dry weigh \\
\hline Replication & 2 & 139.401 & 330.407 & 0.011 & 6209.194 \\
\hline Irrigation(I) & 3 & $162.906^{* *}$ & $1218.725^{\mathrm{ns}}$ & $0.002^{\mathrm{ns}}$ & $1491.306^{\mathrm{ns}}$ \\
\hline $\mathrm{Ea}$ & 6 & 9.128 & 1112.450 & 0.001 & 3173.839 \\
\hline Cultivar (C) & 2 & $292.578^{* *}$ & $378.026^{\mathrm{ns}}$ & $0.006^{\mathrm{ns}}$ & $20780.927^{* *}$ \\
\hline $\mathrm{I} \times \mathrm{C}$ & 6 & $6.244^{\mathrm{ns}}$ & $1037.450^{\mathrm{ns}}$ & $0.001^{\mathrm{ns}}$ & $585.253^{\mathrm{ns}}$ \\
\hline $\mathrm{Eb}$ & 16 & 6.001 & 2096.643 & 0.002 & 903.159 \\
\hline Stage (S) & 6 & $3811.805^{* *}$ & $475638.690^{* *}$ & $0.689^{* *}$ & $617191.192^{* *}$ \\
\hline $\mathrm{I} \times \mathrm{S}$ & 18 & $50.736^{* *}$ & $8346.032^{* *}$ & $0.007^{* *}$ & $5004.521^{* *}$ \\
\hline $\mathrm{C} \times \mathrm{S}$ & 12 & $20.294^{* *}$ & $1532.738^{\mathrm{ns}}$ & $0.003^{\mathrm{ns}}$ & $2650.199^{*}$ \\
\hline $\mathrm{I} \times \mathrm{C} \times \mathrm{S}$ & 36 & $4.502 \mathrm{~ns}$ & $5021.230^{\mathrm{ns}}$ & $0.001^{\mathrm{ns}}$ & $678.531 \mathrm{~ns}$ \\
\hline $\mathrm{Ec}$ & 144 & 5.569 & 16654.167 & 0.002 & 1218.758 \\
\hline Total & 251 & & & & \\
\hline $\mathrm{CV} \%$ & & 13.26 & 22.45 & 17.69 & 27.63 \\
\hline
\end{tabular}

**** Significant at $\mathrm{P} \leq 0.05$ and $\mathrm{P} \leq 0.01$, respectively

Seed dry weight of chickpea for different irrigation treatments and cultivars increased with improving seed development up to a point where maximum weight was obtained (mass maturity). Thereafter, seed weight slightly decreased, due to shedding of large seeds. Maximum seed weight decreased with decreasing water availability. Azad had the highest seed weight at all stages of seed development, but changes in seed weight of Arman and Jam were almost similar. Maximum seed weight was achieved at 40-45 days after flowering, depending on water supply and cultivar (Fig. 1).
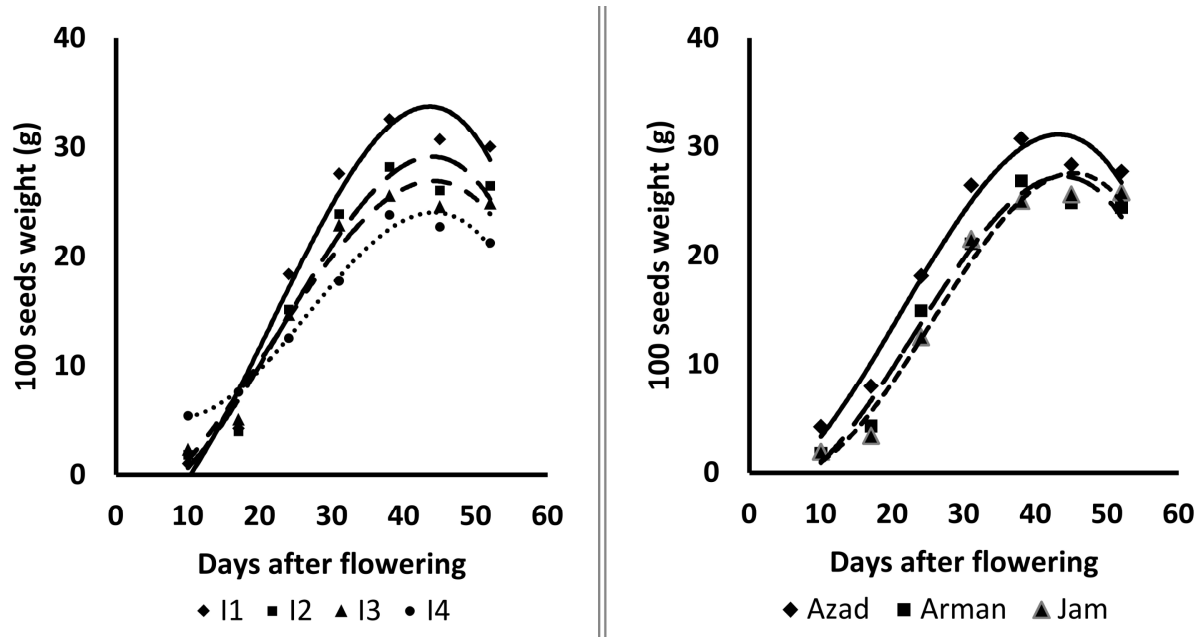

Fig. 1. Changes in seed weight of chickpea for different irrigation treatments and cultivars, harvested at different stages of maturity

$I_{1}, I_{2}, I_{3}$ and $I_{4}$ : irrigation after $70,100,130$ and $160 \mathrm{~mm}$ evaporation from class A pan, respectively 
Germination percentage and rate of chickpea for different irrigation treatments increased with increasing seed weight, but maximum values of these quality parameters were obtained 7 to 10 days after the end of seed filling (mass maturity). Thereafter, germination percentage slightly decreased, but no considerable changes in seed germination rate were observed. Maximum germination percentage and rate decreased with increasing water deficit (Fig. 2).
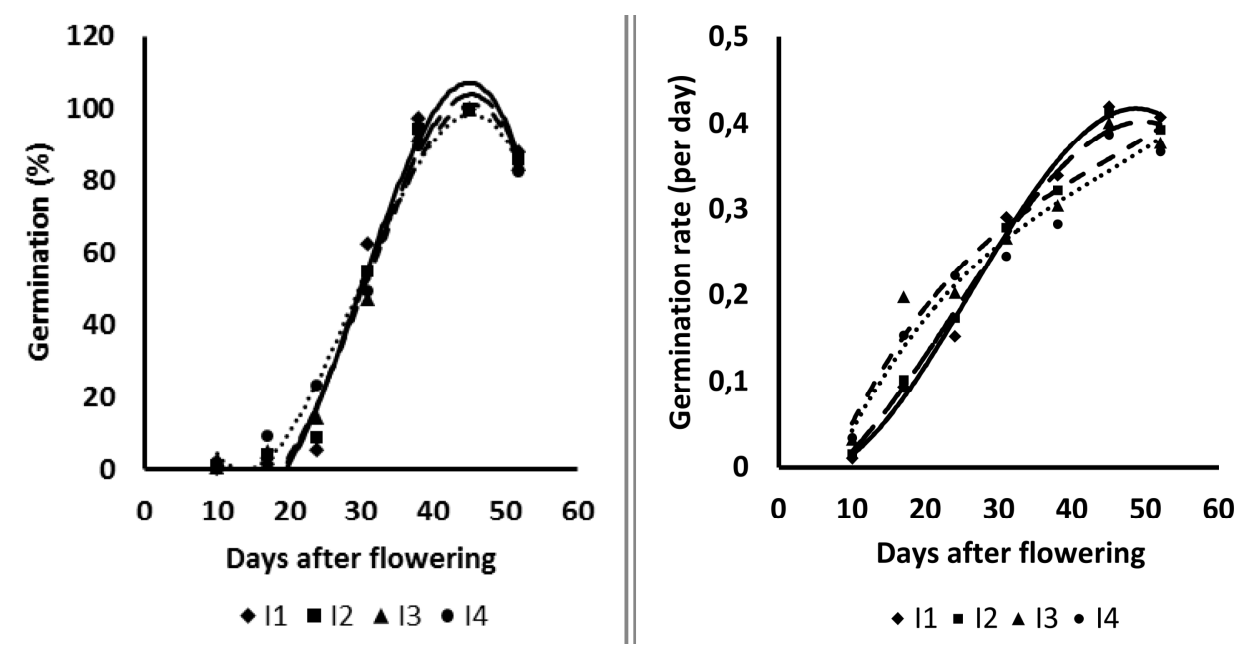

Fig. 2. Changes in germination percentage and rate of chickpea seeds harvested at different stages of maturity under different irrigation treatments

$\mathrm{I}_{1}, \mathrm{I}_{2}, \mathrm{I}_{3}$ and $\mathrm{I}_{4}$ : irrigation after 70,100,130 and $160 \mathrm{~mm}$ evaporation from class A pan, respectively

Seedling dry weight of chickpea for different irrigation treatments and cultivars increased with progressing seed development up to 7 to 10 days after mass maturity and then started to decrease. The highest seedling dry weight at all stages of seed development was obtained for Azad cultivar, but seedling dry weight for Arman and Jam cultivars was almost similar. Seedling dry weight for seeds produced under limited irrigations $\left(\mathrm{I}_{3}\right.$ and $\left.\mathrm{I}_{4}\right)$ at the earlier harvests was up and their maximum values were achieved earlier than the others (Fig.3). 

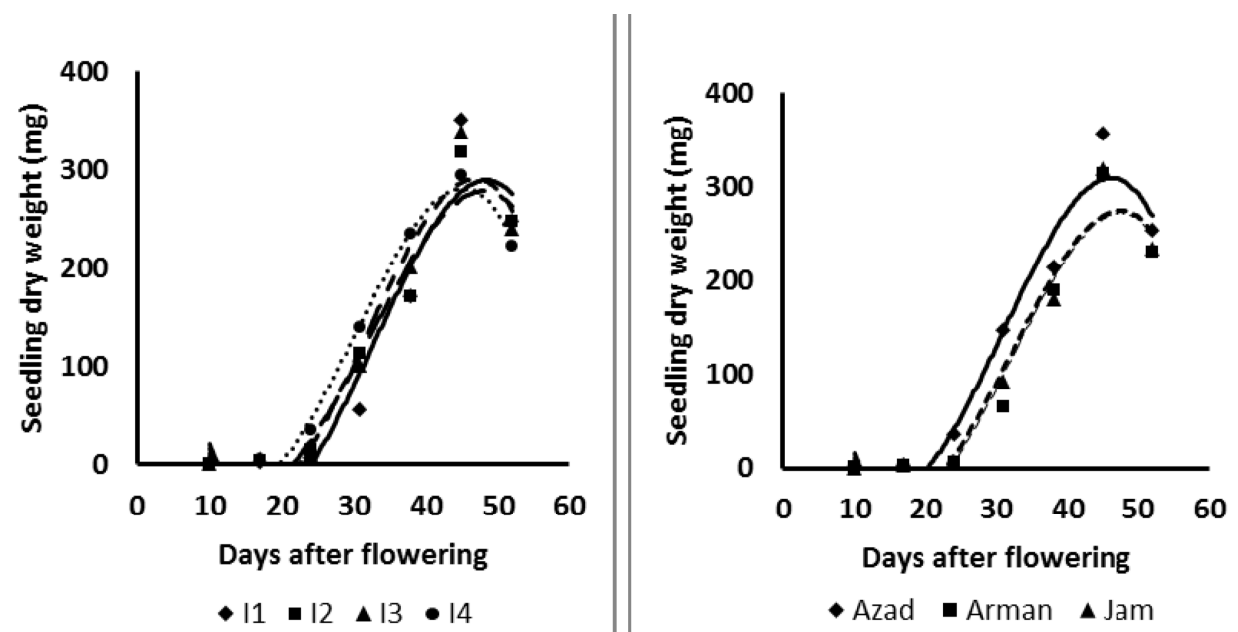

Fig. 3. Changes in seedling dry weight of chickpea seeds harvested at different stages of maturity, for different irrigation treatments and cultivars

$I_{1}, I_{2}, I_{3}$ and $I_{4}$ : irrigation after 70,100,130 and $160 \mathrm{~mm}$ evaporation from class A pan, respectively

\section{DISCUSSION}

Seed filling rate and maximum seed weight of chickpea decreased with increasing irrigation intervals (Fig. 1), but water deficit had no significant effects on seed quality as measured by germination percentage and rate and also by seedling dry weight (Table 1), although maximum germination percentage and rate slightly decreased with decreasing water supply (Fig. 2). No significant effects of water limitation on seed quality were also reported for maize and sorghum (Ghassemi-Golezani et al., 1997), common bean (Ghassemi-Golezani and Mazloomi-oskooyi, 2008), faba bean (GhassemiGolezani and Hosseinzadeh-Mahootchy, 2009) and chickpea (GhassemiGolezani et al., 2010b).

Significant differences in seedling dry weight among chickpea cultivars (Table 1, Fig. 3) can be at-tributed to significant variation in seed weight affected by genetic constitution (Table 1, Fig. 1). Seeds of Azad were comparatively large at different stages of development (Fig. 1) and produced the largest seedlings at all stages (Fig. 3). Such effects of seed size on seedling size were also approved by Perry (1980) and Ghassemi-Golezani et al., (2010b).

Maximum seed germination percentage, ger-mination rate and seedling dry weight were obtained 7 to 10 days after mass maturity, depending on water supply and cultivar (Figs 1, 2 and 3). These results are compatible with those reported for rice (Ellis et al., 1993), wheat (Lehner et al., 2006), tomato (Demir and Samit, 2001; Demir et al., 2008), common been (Ghassemi-Golezani and Mazloomi-Oskooyi, 2008), faba been (Ghassemi- 
Golezani and Hosseinzadeh-Mahootchy, 2009) and oilseed rape (GhassemiGolezani et al., 2011b). Low quality of seeds at the early stages of development was due to immaturity, while the decline in germination percentage and seedling dry weight at later stages (Fig. 2 and 3) caused by seed aging on mother plant (Ghassemi-Golezani and Mazloomi-Oskooyi, 2008).

Seed quality is a limiting factor affecting, not only germination capacity but also emergence potential, field stand and uniformity, seedling growth and finally crop productivity. The significance of seed quality is more pronounced under adverse seed sowing conditions. Water stress had no significant effect on seed quality of chickpea cultivars (Table 1), but it can significantly reduce seed weight (Fig. 1) and yield (Ghassemi-Golezani et al., 1997). Thus, high quality seeds of chickpea cultivars could be produced, if seeds were harvested shortly after mass maturity. High quality seeds can perform well in the field, ensuring op-timum stand establishment and satisfactory yield under a wide range of environmental conditions (GhassemiGolezani et al., 2010a).

\section{REFERENCES}

Demir I, Ashirov AM, Mavi K. 2008. Effect of seed production environment and time of harvest on tomato (Lycopersicon esculentum) seedling growth. Res J Seed Sci. 1:1-10.

Demir I, Ellis RH. 1992. Changes in seed quality during seed development and maturation in tomato. Seed Sci Res. 2: 81-87.

Demir I, Ellis RH. 1993. Changes in potential seed longevity and seedling growth during seed development and maturation in marrow. Seed Sci Res. 3: 247-257.

Demir I, Samit Y. 2001. Seed quality in relation to fruit maturation and seed dry weight during development in tomato. Seed Sci Tech. 29: 453-462.

Ellis RH, Hong TD, Jackson MT. 1993. Seed production environment, time of harvest and potential longevity of seeds of three cultivars of rice (Oryza sativa L.). Annals Bot. 72: 583-590.

Ellis RH, Pieta Filho C. 1992. Seed development and cereal seed longevity. Seed Sci Res. 3: 247-257.

Ellis RH, Roberts EH. 1980. Towards a rational basis for testing seed quality. In: Seed production, (Hebblethwaite PD. ed.), Butterworths, London, p. 605-635.

Ghassemi-Golezani K. 1992. Effects of seed quality on cereal yields. PhD Thesis, Univesity of Reading (UK), p. 205-222.

Ghassemi-Golezani K, Hosseinzadeh-Mahootchy A. 2009. Changes in seed vigour of faba bean (Vicia faba L.) Cultivars During Development and Maturity. Seed Sci Technol. 37: 713-720.

Ghassemi-Golezani K, Khomari S, Dalil B, Hosseinzadeh-Mahootchy A, Chadordooz-Jeddi A. 2010b. Effects of seed aging on field performance of winter oilseed rape. J Food Agric Environ. 8:175-178.

Ghassemi-Golezani K, Lotfi R, Norouzi M. 2012. Seed quality of soybean cultivars affected by pod position and water stress at reproductive stages. Int J Plant Environ Sci. p. 119-125.

Ghassemi-Golezani K, Mazloomi-Oskooyi R. 2008. Effect of water supply on seed quality development in common bean (Phaseolus vulgaris var.). Int J Plant Prod. 2: 117-124.

Ghassemi-Golezani K, Mousabeygi T, Raey Y, Aharizad S. 2010a. Effects of water stress and pod position on the seed quality of chickpea (Cicer arietinum L.) cultivars. Not Bot Hort Agro Bot Cluj. 38: 114-118.

Ghassemi-Golezani K, Sheikhzadeh Mosaddegh p, Shakiba MR, Mohamadi A, Nasrollahzadeh S. 2011 b. Development of seed physiological quality in winter oilseed rape (Brassica napus L.) cultivars. Not Bot Hort Agrobot Cluj. 39: 208-212.

Ghassemi-Golezani K, Soltani A, Atashi A. 1997. The effect of water limitation in the field on seed quality of maize and sorghum. Seed Sci Technol. 25: 321-323.

Ghassemi-Golezani K, Tajbakhsh Z, Raey Y. 2011a. Seed development and quality in maize cultivars. Not Bot Hort Agrobot Cluj. 39: 178-182. 
Harington JF. 1972. Seed storage and longevity. In: Seed biology, (Kozlowski TT. ed.), Academic Press, New York, p. 145-245.

ISTA. 2010. International rules for seed testing, seed vigor testing. Chapter 15, p. 1-57.

Lehner A, Bailly C, Flechel B, Poels P, Comea D, Corbineau F. 2006. Changes in wheat seed germination ability, soluble carbohydrate and antioxidant enzyme activities in the embryo during the desiccation phase of matuiration. J Cereal Sci. 43: 175-182.

Mathews S, 1980. Controlled deterioration: A new vigour test for crop seeds. In: Seed Production, (Hebblethwaite PD. ed.), London, Butterworths, p. 647-660.

Perry DA. 1977. A vigour test for seeds of barley (Hordeum vulgar L.) based on measurement of plumule growth. Seed Sci Technol. 5: 709-719.

Perry DA. 1980. The concept of seed vigour and its relevance to seed production techniaues. In: Seed production, (Hebblethwaite PD. ed.), London, Butterworths, p. 585-591.

Sanhewe AJ, Ellis RH. 1996. Seed development and maturation in Phaseolus vulgaris. I. Ability to Germinate and to Tolerate Desiccation. J Exp Bot. 47: 949-958.

Tekrony DM, Egli DB. 1997. Accumulation of seed vigour during development and maturation. In: Basic and applied aspects of seed biology. (Ellis RH, Black M, Murdoch AJ, Hong TD. eds.) Kluwer Academic Publishers, Dordercht, p. 369-384.

Zehtab-Salmasi S, Ghassemi-Golezani K, Moghbeli S. 2006. Effect of sowing date and limited irrigation on the seed yield and quality of dill (Anethum graveolens L.). Turk J Agric For. 30: 281-286. 